\title{
Imágenes paceñas: El mago de la ciudad paceña moderna
}

\author{
Tara Daly y Raquel Alfaro \\ Marquette University, University of Rochester
}

\begin{abstract}
In this essay we disentangle what Jaime Saenz conceives of as the "magic" of La Paz as elaborated in Imágenes paceñas. We analyze magic from three complementary angles. First, we focus on the relationship between magic and unease. This take on magic is associated in the text, in an unexplicit and tangential way, with non-Western culture; that is, the Aymara indigenous. Our second point of entry intersects the first. The version of La Paz that Saenz depicts is moved by unfamiliar cultural forces. As a consequence, it is a product of, and produces, a distinct form of inhabiting characterized by a temporality that troubles that of modernity; this, too, results in a sense of magic. Finally, in our third approach to magic, we analyze the tensions derived from the visual and written registers Saenz combines in this text. In the montage forged between text and photography, writing is employed to maintain somewhat hidden, and for that reason alive, the magical aspects of the city. And so, the author is in part a magician: he reveals something only to distract, all in the name of protecting the very conditions that enable his art.

Keywords

Imágenes paceñas, Jaime Saenz, magic, montage, photography
\end{abstract}




\section{Resumen}

En este ensayo desenredamos lo que Jaime Saenz concibe como la "magia" de La Paz en Imágenes paceñas. Analizamos la magia desde tres ángulos complementarios. Primero, prestamos atención a la bisagra magia/inquietud. Esa primera magia es asociada en el texto con una cultura no-occidental, la aymara. Nuestro segundo punto de entrada se cruza con el primero. La Paz es movida por fuerzas ajenas $y$, en consecuencia, se produce una forma de habitar distinta determinada por un eje temporal opuesto a la modernidad importada. Esta suspensión del tiempo moderno también genera una temporalidad mágica. En la tercera entrada, explicamos las tensiones derivadas de la combinación de registro escrito y visual. En el montaje de escritura y fotografía, la escritura es empleada para mantener ocultos, y por eso mismo vivos, los aspectos mágicos de la ciudad. El autor así aparece como una suerte de mago, quien revela algo sólo para distraer con el fin de proteger las mismas condiciones que posibilitan su arte.

Palabras clave

Fotografía, Imágenes paceñas, Jaime Saenz, magia, montaje

Dentro de la extensa obra del poeta y escritor boliviano Jaime Saenz figura Imágenes paceñas (1979), un libro que guarda un registro de la ciudad de La Paz de la década de los 70 por medio del tramado de viñetas de una serie de lugares y personajes paceños que "representan [para el autor] de modo inequívoco el carácter de la ciudad" (13). Cada capítulo del texto, en ese sentido, ofrece una descripción poética mínima de un componente particular de La Paz - plaza, parque, vecindario, cerro- y semblanzas de aquellos personajes que expresan el espíritu de esta peculiar urbe -soldador, lustrabotas, aparapita, chola. Al mismo tiempo, cada uno de estos trozos literarios viene acompañado por una fotografía en blanco y negro que no tiene plena relación con el texto escrito. Esto genera un diálogo silente entre el registro visual y el escrito creando una experiencia contradictoria. Ampliando esta contradicción, Saenz expresa temor de que la modernización de la urbe paceña haga desaparecer lo que la hace única, su magia, pero a la vez afirma que esto es imposible. Precisamente por ser mágica, La Paz sería capaz de hacerle frente a las fuerzas transformadoras del progreso. Así, aunque el avance del progreso parece irrefrenable, hay una fuerza mágica en el corazón de la ciudad que conseguirá preservar su carácter enigmático y evitar que el mismo sea borrado por los procesos modernizadores. En esta realidad escondida de La Paz, donde se encontraría su fuerza mágica, estaría 
interesado el autor. En sus propias palabras: "[d]ando por sentado que la ciudad de La Paz tiene una doble fisonomía y admitiendo que mientras una se exterioriza la otra se oculta, hemos querido dirigir nuestra atención a esta última" (9).

En este ensayo nos concentramos en la idea de magia acuñada por el autor para tratar de discernir la fisonomía oculta de La Paz. Consideramos la magia desde tres ángulos. Primero, prestamos atención a la bisagra magia/inquietud. Aquello que hace singular a la urbe paceña es algo que a la vez produce resquemor e incertidumbre porque su origen desconocido (cara al propio Saenz), y su curso, no pueden ser controlados. En este sentido, esa magia es asociada, en el texto, de un modo tangencial y no explícito, con una cultura no-occidental, la aymara. ${ }^{1}$ Allí la razón por la que se repite enfáticamente que La Paz es una ciudad andina. Nuestro segundo punto de entrada se cruza con el primero. Para Saenz, La Paz es movida por fuerzas culturales ajenas al marco de pensamiento occidental dominante. En consecuencia, es producto de y produce una forma de habitar distinta. Este habitar está determinado por las condiciones que establece la singular topografía de la hoyada paceña, pero también por un ritmo cultural que se opone y suspende el fluir del tiempo moderno. Este cruce de espacio y tiempo haría de La Paz mágica, e Imágenes paceñas intentaría revelar este contenido mágico. Como tercera entrada, explicaremos las tensiones derivadas de la combinación de registro escrito y visual, las cuales revelan lo complicado de ese habitar rastreado por Saenz en este libro. Imágenes paceñas utiliza modos de representación distintos para permitir que el lector habite el texto. En el montaje de escritura y fotografía, la escritura es empleada estratégicamente para mantener ocultos $y$, por eso mismo, vivos, los aspectos mágicos de la ciudad. Este entretejido de texto e imagen revela y esconde la ciudad a la vez, y el autor aparece como una suerte de mago que revela algo sólo para distraer y producir una realidad inesperada y sorpresiva.

\footnotetext{
${ }^{1}$ Elizabeth Monasterios afirma que la poética saenceana (y pensamos, por extensión, su narrativa): “'integra' al aymara (y al descendiente de aymara) en la cultura nacional de una manera original, pues la tal integración no es planteada a partir de una nostalgia por el aymara de la antigüedad, ni a través de acciones pedagógicas que lo civilicen [...] Lo que propone la obra de Saenz en la inserción de la lógica cultural aymara (radicalmente anti-hegemónica y portadora de una racionalidad distinta a la occidental) en la estructura de la cultura oficial" (Dilemas de la poesía del fin de siglo 19).
} 


\section{La magia y la inquietud de la ciudad andina}

La condición mágica de la ciudad es un sine qua non para Saenz. Tal como es señalado en el epíteto de nuestro ensayo, Saenz afirma que "no hay ciudad que no sea mágica" (10). La vivencia que se tiene en toda urbe, al parecer del autor, dota a estos escenarios de una innegable aura mágica. Sin embargo, entre estos lugares se destaca La Paz como una expresión mágica singular y única: "[m]ás lo mágico, en cuanto concierne a nuestra ciudad en particular, ofrece una serie de matices, a cuál más inquietantes" (10) en tanto "es una ciudad andina, que no europea o norteamericana" (11). Se ve que la magia de la urbe paceña así se originaría en el carácter perturbador de los lugares y personajes descritos en Imágenes paceñas, los cuales son manifestaciones de lo andino, escondidas por evidentes y evidentes por escondidas. En este sentido, la magia particular de La Paz es resultado de la interacción entre su topografía y sus habitantes.

La Paz es una hoyada situada en la cordillera de los Andes, lo que la coloca en la región andina. A ello se suma el hecho de que está "[p]residida por el Illimani, por el Murarata y el Huayna Potosí, que se cuentan entre los mayores colosos del Ande, con una geografía como probablemente no la hay igual o parecida [...] alzándose a una altura de 3.600 metros sobre el nivel del mar" (10-11). Esta realidad objetiva provoca desconcierto al parecer del autor. Es curioso, pero a la vez inquietante, encontrar una ciudad situada entre montañas inmensas e imaginar a habitantes que realizan las mismas actividades que otros desempeñan en otras ciudades latinoamericanas, estadounidenses o europeas, con cuerpos acostumbrados a un consumo reducido de oxígeno debido a la altura. Además, su calidad de hoyada contiene el crecimiento de La Paz. No le permite extenderse y crecer horizontalmente, y la fuerza a un crecimiento siempre vertical, si es que tal desarrollo es posible. Al igual que el cementerio (que puede ser pensado como una metonimia de La Paz), que "evidentemente no se expande, ni en sentido horizontal ni en sentido vertical" (31), esta ciudad en apariencia está limitada por estar rodeada de montañas. De allí que las observaciones de Saenz sobre el cementerio paceño, cuya expansión es imposible por estar ubicado en medio de otras construcciones - "cabría preguntarse en qué sentido se expande"; "¿Por qué no se expande el cementerio?" (31) - puedan ser traspuestas a su reflexión sobre la topografía de La Paz. La topografía es mágica en la medida en que desafía las convenciones de los diseños urbanos tradicionales, que imaginan la ciudad como un núcleo que va a necesariamente crecer y cuya expansión no 
puede sino ser horizontal. Es mágica por su desafío directo a las leyes de gravedad, produciendo una ilusión óptica a causa de su densidad y verticalidad.

Por estar ubicada a 3.600 metros sobre el nivel del mar, la ciudad acoge sujetos con organismos que se han adaptado a la falta de oxígeno de las alturas. Esto dota a estos cuerpos de una enorme capacidad de adaptación y resistencia a condiciones extremas, en términos objetivos. En su sustrato subjetivo, hace que estos pobladores vivan la falta, la escasez, siempre en relación con su opuesto: el exceso. $Y$ es esta tensión que los convierte en los verdaderos pobladores de La Paz para Saenz. Ellos son mágicos porque no se conforman con las normas de comportamiento convencionales bajo el capitalismo y cuestionan en su diario quehacer ese orden. Ejemplos de lo anotado son el aparapita, los vecinos del barrio Tembladerani y los moradores del cerro Laikakota.

¿De dónde ha de sacar un pobre obrero, por ejemplo, para pagar una camioneta, en tratándose de una suma que tranquilamente equivale a dos o tres días de su subsistencia? Le urge llevar un colchón y una cuja a su casa; $y$ no es que tenga reparos en cargar el bulto sobre sus propias espaldas, sino que no siempre tiene las fuerzas suficientes para ejecutar una faena de tal naturaleza, que al mismo tiempo requiere maña, destreza y costumbre, cosas éstas que al aparapita le sobran, siendo bien sabido que puede llevar perfectamente un peso de seis quintales a una distancia de veinte o treinta cuadras sin hacer un solo descanso. (135)

La escasez de recursos económicos, unida a la falta de enorme fuerza física, hace que en el caso de necesitar el traslado de un objeto extremadamente pesado (seis quintales) de un punto a otro de la ciudad (veinte o treinta cuadras), un paceño opte por tomar los servicios de otro paceño, el aparapita. El aparapita, una persona que carece de fuerza extraordinaria y que en cambio posee en exceso "maña, destreza y costumbre", cumple la tarea, supliendo la falta que el otro tiene con el exceso propio. ${ }^{2}$ Por su parte, el otro, quien toma sus servicios, tiene exceso económico frente al aparapita. Él va a pagar por sus servicios. Pero además, tiene un exceso de libertad frente a éste porque es él quien decide cuánto pagar al aparapita por sus servicios. El hecho de que el otro decida cuánto valen los

\footnotetext{
2 De acuerdo a Saenz, quien contrata lo servicios del aparapita puede o no tener fuerza para levantar el objeto que el aparapita ha sido contratado para cargar. Lo que significa que el aparapita no tiene una fuerza sobrehumana. Esta falta es suplida por maña, destreza y costumbre, que le permiten ejecutar tareas que requieren gran fortaleza física sin realmente tenerla.
} 
servicios del aparapita, resta autonomía a este último: "El aparapita es un hombre libre, hasta donde puede serlo un hombre como él, que debe ganarse el pan dependiendo de lo que buena - o malamente- le pagan" (137). De esto se deriva otra expresión de la escasez combinada con el exceso: el aparapita prefiere beber a comer, opta por reventar bebiendo, a morir de hambre: "Pues bebe hasta reventar, y por paradoja, mal puede permitirse el lujo de morir de hambre, ya que su gran sentido de dignidad se lo prohíbe" (137). ${ }^{3}$ Parece desafiar las reglas mínimas de la subsistencia y, por eso, es mágico.

Los moradores de las concavidades del cerro Laikakota muestran una diferente expresión de la condición combativa asociada con la escasez/exceso. Al pie de este cerro que conecta dos barrios tradicionales, Miraflores y Sopocachi, y a orillas del río Choqueyapu, está un basural titánico:

[...] verdadero paraíso para muchedumbres de seres que moran en profundas concavidades del cerro y que, si no son precisamente demonios, como que en rigor no lo son, han de constituir en todo caso una humanidad extraña en grado sumo [...] criaturas, que parecen haberse confabulado para hacer escarnio de los dictados de la sociedad [...] No son ni pordioseros, ni malhechores, ni asesinos, pero son ellos. De nada se ocupan; y si por ventura hacen algo, será escarbar a determinadas horas la basura, y tan sólo para procurarse algunos desperdicios destinados a su alimentación. (127)

Es la extrema pobreza la que ha convertido a estos sujetos en una humanidad extraña. Estos seres, no demoníacos mas humanos, no entran en categorías conocidas ni aceptan etiquetas asociadas a éstas: pordiosero, malhechor, asesino. Son parte del lumpen, pero no por ser el despojo de la sociedad, sino porque voluntaria y activamente rechazan el orden social dominante y se niegan a ser parte de la máquina de producción capitalista. De allí que vivan en las fosas que de forma natural se abren en el cerro y encuentren sus alimentos entre la basura en lugar de adquirirlos con dinero u obtenerlos por medio de la caza. Es la carencia de recursos, entonces, la que hace que estos individuos tengan un exceso de convicción que los hace negarse a ser piezas de la maquinaria de producción capitalista y optar por una existencia al margen de este orden económico fundado en la alienación del ser humano.

\footnotetext{
3 Sobre la figura del aparapita ver Javier Sanjinés, "A Phenomenological Reading of the Andes: Toward the Desublimation of the Cholo" (2003) y Carolyn Wolfenzon, "La figura del aparapita en Felipe Delgado" (2015).
} 
Ahora bien, estos peculiares habitantes no son cuerpos desnudos, en palabras de Agamben. El "aura de leyenda y de misterio" (10) que los rodea tiene un anclaje cultural:

El aparapita es, desde luego, un aymara como cualquier otro; pero un aymara que, sin dejar de ser lo que es, y habiendo por el contrario potencializado las facultades inherentes de su raza, ha querido ubicarse en la ciudad, impulsado empero por ansias irracionales, de meditación, de existencia y de trabajo, que le permitirían conocer y comprender un medio en cierto sentido nuevo, y del que se posesionaría por siempre. (137)

El aparapita es el indígena aymara, migrante del campo, que se asienta en la ciudad. A pesar de vivir en la ciudad no se desvincula de su cultura. Aún más, usa la fuerza que viene de esa su fuente cultural para sobrevivir en la urbe mientras aprende sus secretos para después ocuparla, es decir, hacerla suya. Así, mágicamente, se mantiene extranjero y, es más, extraño al habitar de la ciudad. No abandona sus prácticas culturales ni sus tradiciones para adoptar las formas de comportamiento que son comunes en el centro urbano. Usa las herramientas de supervivencia que su cultura le da, se adapta al ritmo de la ciudad y, poco a poco, va ocupándola como indígena, como aparapita.

Como una expresión de tensión cultural diferente a la del aparapita, se tiene al lustrabotas:

\begin{abstract}
Inventando un lenguaje harto particular y que todos entienden, el lustrabotas ejerce un poderoso influjo sobre el idioma que nosotros los paceños hablamos. Es muy grande su ingenio, y nadie como él para acuñar palabras y nuevos giros, frases altamente expresivas y modos idiomáticos que, por su precisión y originalidad, muy pronto y en definitiva pasan a enriquecer el acervo popular [...] forja[n] las formas renovadoras del idioma paceño. (155)
\end{abstract}

Él no es migrante indígena como el aparapita ni un singular mestizo como la recovera, otro de los personajes que fascina a Saenz. Es más bien un sujeto que lleva en sí el genio de la raza. Su proximidad a grupos de origen indígena que viven en la ciudad ha hecho que comience a actuar, e incluso pensar, como ellos. Es decir, está contaminado por contenidos de la cultura aymara sin ser un aymara. Y gracias a este influjo cultural que lo infecta, es capaz de reinventar la lengua y crear un habla paceña. Pero además de ello tiene los atributos de la recovera destacados por Saenz: la violencia, porque el lustrabotas es conocido por ser un hombre "violento y de avería" que se emborracha mucho, y la condición de esposo y padre ejemplar, puesto que es 
"amante del hogar", idolatra a sus hijos y trabaja incansablemente por ellos (155). La tensa coexistencia de estos atributos contradictorios hace mágico a este personaje porque la imagen que proyecta en espacios públicos funciona como una suerte de espejismo que protege su forma de habitar distinta.

Lo anotado hasta este punto permite afirmar entonces que la singular ubicación geográfica y peculiaridad topográfica de La Paz no son los únicos elementos que la definen como un fenómeno inquietante. Otros aspectos están en juego y es la curiosa combinación de estos factores objetivos y subjetivos, de la cual se ha dado ejemplos, de donde deriva la magia de la urbe paceña. Ahora bien, el progreso hace que el ciudadano común no se percate de esta magia y la misma sea reprimida en un inconsciente colectivo. Este fenómeno produce a la vez fascinación y extrema preocupación en Saenz.

La modernización de la urbe paceña no tiene el poder para eliminar su esencia mágica y las manifestaciones inquietantes que produce, como ser: montaña, río, recovera, aparapita, etc. Son estas últimas, convertidas en fantasmas por el flujo arrasador de la modernidad, las que volverían imposible que la singularidad de La Paz deje de existir. Lo mágico deja de ser percibido, pero no se pierde jamás. ${ }^{4}$ Para mostrar la urbe andina, inquietante y escondida, la propuesta literaria saenceana genera una sensación de extrañeza en el lector para alterar su mirada y hacer que la misma pueda posarse y descubrir retazos de mundos eclipsados por la modernidad.

Esta sensación de extrañeza puede ser vinculada al concepto de unheimlich trabajado por Kristeva. En Das Unheimliche (1919), de acuerdo a la lectura de Kristeva, Freud explica que se reestablece el lazo que relaciona heimlich (lo conocido, lo familiar, lo visible) con su opuesto unheimlich (lo desconocido, lo extraño, lo invisible) cuando aquello que suponemos ajeno se revela ante nosotros como una realidad conocida pero reprimida en nuestro inconsciente y solo por eso ahora extraña para nosotros. Entonces, cuando lo reprimido se abre paso y se manifiesta en nuestro consciente, se produce una experiencia de extrañeza e inquietud: "that which is strangely uncanny would

\footnotetext{
${ }^{4}$ En su lectura crítica de la obra de Walter Benjamin, Margaret Cohen señala que " $[T]$ he magic is that of commodity fetishism, a situation in which social relations between men take on the phantasmagorical form of the relations between things" ("Le Diable a Paris: Benjamin's Phantasmagoria", Profane Illumination 222) [La magia es aquella del fetichismo de la mercancía, una situación en la cual las relaciones sociales entre los hombres asumen la forma fantasmagórica de las relaciones entre las cosas] (Nuestra traducción). La alteración de las relaciones interpersonales que caen en el orden de lo supernatural debido a la alienación generada por el capitalismo es solo una expresión. Ésta viene acompañada de otras y Saenz estaría persiguiendo el rastro de las mismas.
} 
be that which was (the past tense is important) familiar and, under certain conditions (which ones?) emerges" (Kristeva 183. Paréntesis en el original) [eso que es extrañamente inquietante sería aquello que era (el pasado es importante) familiar y, bajo ciertas condiciones (¿cuáles?) emerge (Nuestra traducción). Esto porque nos obliga a enfrentar aquellos sentidos de nuestra realidad y de nosotros mismos que nos hemos esforzado en olvidar y soterrar en nuestro inconsciente. El proyecto literario saenceano que se analiza en este ensayo produciría dicha sensación de extrañeza (uncanny) cuando desinvisibiliza la magia paceña.

"[L]a ciudad ha experimentado un cambio radical y profundo en las últimas tres décadas - vale decir, treinta años. La mitad del tiempo que dura la vida de un hombre; un minuto en la vida de una ciudad" (12), señala Saenz. Esta transformación que está modificando la faz de la urbe paceña de manera precipitada es la expresión del progreso, un progreso que asusta a Saenz. Este progreso está ligado a la aceleración de la producción material y de la articulación de un nuevo orden cultural que tiene como parámetro de referencia a tendencias occidentales dominantes. Es sinónimo además de un movimiento constante e irrefrenable hacia el futuro que impide la preservación de la memoria histórica y por ende cancela la posibilidad de que esta última dé sentido al presente (Avelar 106). Asimismo, determina que culturas no occidentales sean consideradas parte de un tiempo pasado. De este modo, este movimiento vertiginoso hacia el futuro que, en su derrotero, no solo vuelve fugaz al presente y encapsula el pasado para que no afecte al presente y futuro (Benjamin, "Theses on the Philosophy of History", en Illuminations 155), también invisibiliza los mundos indígenas. Saenz, consciente de esto, buscaría hacer presente, de nuevo visible, esa La Paz andina que la modernidad ha reprimido o está en proceso de reprimir en los años 70 .

Lo que está en juego aquí, entonces, es la posibilidad de interrumpir, a través de un trabajo literario, el flujo temporal moderno, abriendo un paréntesis contemporáneo. ${ }^{5}$ Como ya se dijo, dentro del marco epistemológico

\footnotetext{
${ }^{5}$ Avelar, basado en el concepto de "untimely" [extemporáneo] acuñado por Nietzsche, denomina como "contemporaneidad" a aquella cadena de eventos que, anclados en el presente, actúan en contra del tiempo moderno. De este modo, consigue hacer visible lo que este último reprime, invisibiliza y borra. La contemporaneidad en escenarios latinoamericanos, explica Avelar, son flujos temporales que van contra corriente desarmando el artificio creado por la concepción del tiempo moderno y restableciendo vínculos entre presente y pasado quebrados por este último. Este fenómeno abre la posibilidad de imaginar el futuro de un modo distinto.
} 
instaurado por la modernidad, las culturas no-occidentales son pensadas como pasado y superadas por todos los sistemas que vienen después. Por eso, los miembros de estas culturas, y sus prácticas, son concebidos como obstáculos que deben ser eliminados en pro del progreso. Imágenes paceñas intentaría interrumpir esta forma de percibir el tiempo/espacio de la urbe paceña andina, reconciliando pasado y presente. ${ }^{6}$ Con este movimiento, revela lugares y personajes que encarnan lo aymara como parte de nuestro presente, de nuestro mundo, de La Paz, rompiendo la ilusión de que éstos son solo reminiscencias y restos. Y afirma la imposibilidad de que La Paz, como una ciudad andina, desaparezca: "nadie puede negar que La Paz es una ciudad andina; y como tal subsistirá. Así nos lo asegura el espíritu rector que habita la montaña. Esta ciudad no será desvirtuada; no dejará de ser lo que es" (11).

\section{La magia del habitar: entre las inmensas montañas y los rincones olvidados}

Para mejor entender cuál es esa ciudad andina escondida que la escritura saenceana quiere develar es necesario primero discutir lo que significa una ciudad atravesada o resultante del efecto corrosivo del progreso. Benjamin en On Some Motifs in Baudelaire apunta los rasgos determinantes de una ciudad moderna:

Hundreds of thousands of people of all classes and ranks of society jostle past one another; are they not all human beings with the same characteristics and potentialities, equally interested in the pursuit of happiness? [...] And yet they rush past one another as if they had nothing in common or were in no way associated with one another. Their only agreement is a tacit one: that everyone should keep to the right of the pavement, so as not to impede the stream of people moving in the opposite direction. No one even bothers to spare a glance for the others. The greater the number of people that are

\footnotetext{
${ }^{6}$ A diferencia de otros escritores quienes han estudiado las lógicas culturales de los grupos andinos (aymara y quechua) y cuya producción literaria revela un conocimiento profundo de estas culturas, como por ejemplo José María Arguedas en Perú y Alison Spedding en Bolivia, Saenz no muestra (al menos explícitamente) estar familiarizado con la lógica cultural andina. No obstante, su intuición poética le permite inferir formas de pensamiento ligadas a esta lógica en general y la aymara en particular. Así, en Imágenes paceñas se pone en juego -de manera tangencial- una conceptualización del tiempo andino: una espiral en donde se tejen pasado y presente para producir el futuro (ver, al respecto, Simón Yampara, "Convivencia andina: vivir y convivir en armonía integral - Suma qamaña").
} 
packed into a tiny space, the more repulsive and offensive becomes the brutal indifference, the unfeeling concentration of each person on his private affairs. (187)

[Cientos de miles de personas de toda clase y rango de la sociedad se empujan, ¿no son todos seres humanos con las mismas características y potencias, igualmente interesados en la búsqueda de la felicidad? [...] Y sin embargo, se precipitan el uno al otro, como si no tuvieran nada en común o que en ninguna manera se relacionaran. Su único acuerdo es tácito: que todos deben quedarse a la derecha de la calle para no impedir la oleada de gente que camina en dirección opuesta. Nadie ni siquiera se mira. Cuanta más gente se abarrota en un espacio pequeño, más repulsiva y ofensiva es la brutal indiferencia, la concentración insensible de cada persona en sus propios asuntos privados] (Nuestra traducción)

Las ciudades modernas nacientes en el siglo XIX reemplazaron la comunidad por la multitud, una masa amorfa de seres alienados, que han perdido su humanidad y son incapaces de ver/se o reconocer/se al/en el otro. Nacida de migraciones masivas que respondían a la necesidad de mano de obra de la industria emergente, esta masa, cuando no está confinada y apretujada en sitios estrechos como una fábrica, por ejemplo, se mueve constante y mecánicamente: siempre hay un lugar al que ir y siempre parece faltar tiempo para llegar al destino. Esto impide que el individuo observe su entorno; no sólo se ignora a aquella persona sentada frente a uno en el tranvía, sino también se desconoce las particularidades del propio tranvía, el camino que abre, etc. Tampoco se ve a través del cristal de las ventanas el cielo o, a lo lejos, las colinas. Además, el sujeto aquí está permanentemente bombardeado por estímulos que impiden su experiencia en términos benjaminianos:

Man's inner concerns do not have their issueless private character by nature. They do so only when he is increasingly unable to assimilate the data of the world around him by the way of experience. Newspapers constitute one of many evidences of such an inability. If it were the intention of the press to have the reader assimilate the information it supplies as part of his own experience, it would not achieve its purpose. But its intention is just the opposite, and it is achieved: to isolate what happens form the realm in which it could affect the experience of the reader. The principles of journalistic information (freshness of the news, brevity, comprehensibility, and, above all, lack of the connection between the individual news items) contribute as much to this as does the make-up of the pages and the paper's style. (158-159) 
[Las aspiraciones interiores del hombre no tienen por naturaleza un carácter privado tan irremediable. Sólo lo adquieren después de que disminuyen las probabilidades de que las exteriores sean incorporadas a su experiencia. El periódico representa uno de los muchos indicios de esa disminución. Si la Prensa se hubiese propuesto que el lector haga suyas las informaciones como parte de su propia experiencia, no conseguiría su objetivo. Pero su intención es la inversa y desde luego la consigue. Consiste en impermeabilizar los acontecimientos frente al ámbito en que pudiera hallarse la experiencia del lector. Los principios fundamentales de la información periodística (curiosidad, brevedad, fácil comprensión y sobre todo desconexión de las noticias entre sí) contribuyen al éxito igual que la compaginación y una cierta conducta lingüística] (Traducción de Jesús Aguirre 127).

Como consecuencia de lo anotado, los individuos que moran en estos nuevos centros urbanos viven aislados unos de otros, no son capaces de formar una comunidad y vivir en armonía con el mundo circundante. Saenz percibe el advenimiento de un fenómeno similar en su ciudad aunque, claro está, con distancias respecto a la experiencia europea. La modernización de La Paz no es equivalente a la emergencia de ciudades europeas en el siglo XIX de las que nos habla Benjamin. Estas urbes europeas son el resultado de dinámicas socioeconómicas que coinciden con la emergencia de la industrialización y desarrollo tecnológico que inducen movimientos humanos masivos y su concentración en espacios limitados. Si bien la transformación de La Paz saenceana tiene también que ver con el desarrollo industrial y cambios generados por la introducción de avances tecnológicos, se inscribe en un momento histórico distinto. Responde a procesos de modernización implementados en escenarios marcados por su ingreso tardío a la modernidad y al capitalismo, ocupando, por lo mismo, un sitial marginal respecto a Europa y Estados Unidos. ${ }^{7}$

Se suma a ello el hecho de que estos centros urbanos además se inscriben y escriben sobre diseños de ciudades coloniales. ${ }^{8}$ Esta superposición de

\footnotetext{
7 Mientras las ciudades europeas son resultado del paulatino desarrollo de la industrialización, en Latinoamérica las ciudades, tanto en la época colonial como en el período republicano, son creadas con el propósito expreso de "civilizar/evangelizar" y "modernizar", siempre preservando y proyectando lo occidental sobre todo lo nooccidental; vale decir, culturas indígenas y afrolatinas.

${ }^{8}$ Como Ángel Rama lo señala en La ciudad letrada, el mapa de las ciudades del Nuevo Mundo es la trasposición de un orden social jerárquico a un orden distributivo geométrico. Todas las ciudades coloniales comparten un modelo: se tiene una plaza central, el corazón, desde la cual la urbe va abriéndose en círculos concéntricos. Esta construcción imaginaria - núcleo del poder, centro de la administración colonial y eje
} 
diseños urbanos genera tensiones, pero también la consolidación de ciertas estructuras coloniales, reforzando la colonialidad interna (ver Gonzáles Casanova 1963 y Aníbal Quijano 2007) de la sociedad paceña. La suma del impulso civilizador que está tras la fundación de la ciudad en la época colonial y el modernizador que quiere transformar La Paz, provoca que se vuelvan mucho más gruesas las murallas que protegen la ciudad letrada. Este proceso aumenta la distancia con los iletrados ${ }^{9}$ y destruye un modo de habitar la ciudad que escapa a la razón occidental, ese que permite experimentar las montañas y los ríos, los callejones y callejuelas, los aparapitas, los vendecositas.

La identificación del problema que conlleva la modernización de la urbe paceña permite a Saenz descorrer otras persianas, construidas por la colonia, que nos han mantenido encerrados en una burbuja letrada, ajenos y alejados de otras fuentes culturales. Ve también como la cotidianeidad moderna está lentamente arrancando al paceño tanto de su colectivo humano como de su entorno:

[...] el hombre que se reúne con la multitud y se sumerge en ella, siempre ha de encontrarse completamente solo y confundido al mismo tiempo, cual una gota de agua que pugna por reconocerse en el mar. Pues en tal sentido, si el hombre busca un remedio allí donde precisamente no lo hay, es porque la soledad no se remedia sino con la propia soledad. De ahí que la magia de la ciudad, si se quiere, no es otra cosa que la magia de la soledad. (10)

Asimismo, observa el autor que La Paz puede frenar este proceso: "nadie puede negar que La Paz es una ciudad andina; y como tal subsistirá. Así nos lo asegura el espíritu rector que habita la montaña" (11). La montaña rige a ciudad de La Paz como punto geográfico de referencia, pero también como huaca, entidad mágica rectora en las culturas indígenas y asociada con un modo de conocer el mundo distinto. De este cruce emerge un modo de habitar próximo a aquel del cual habla Heidegger: la coexistencia armónica con el entorno.

Según Heidegger, en los tiempos pre-modernos, construir es habitar porque toda construcción busca siempre cuidar/abrigar y al mismo tiempo

\footnotetext{
de la razón imperial- no responde a la ciudad real. Al contrario, se opone a ella y la niega como posibilidad de formación social de manera sistemática.

${ }^{9}$ Aquí el término iletrado tiene un sentido amplio. No solo refiere al individuo que no tiene conocimiento y dominio de la escritura, sino también a quienes por pertenecer a culturas no-occidentales, son pensados como incapaces de comprender y exitosamente navegar escenarios donde la lógica cultural occidental dominante impera.
} 
crear un albergue. Este habitar entonces construye una morada, un camino, un puente, para habitar en armonía con el entorno circundante: "el habitar es más bien siempre ya una morada junto a las cosas" (Heidegger 155). Esta forma de entender el construir/habitar se opone al acto de construir en el discurso de la modernidad: transformar nuestro medio ambiente para amoldarlo a nuestras necesidades, como resultado de y la continuación de la alienación del ser de su hábitat.

La forma heideggeriana de entender el habitar puede ser muy bien enriquecida por el concepto del suma q'amaña acuñado en los últimos años por pensadores indígenas de la región andina. Xavier Albó hace un rastreo etimológico de esta expresión aymara y señala que "q'ama", como sufijo, significa coexistencia con animales, con plantas, en comunidad, con sujetos pertenecientes a otras comunidades, pero una que siempre supone armonía. "Q'amaña" - de una manera muy próxima al habitar heideggeriano que significa cuidar, custodiar y velar por algo/alguien - entonces hace referencia a la "convivencia social pero también ecológica" que a su vez implica un "'cuidar' y 'criar' la vida, como algo que hacemos juntos, en familia; connota además toda las maneras en que cuidamos y protegemos nuestros cultivos y el medio ambiente" (133).

Por su parte, "suma" significa "precioso, excelente, acabado, perfecto", (135) pero fuera de un sistema comparativo ligado a un ordenamiento jerárquico de la realidad. A lo precioso no se opone lo espantoso o carente de valor; lo excelente no se levanta frente a lo desastroso; lo acabado no supera a lo inacabado; y lo perfecto no es preferible a lo imperfecto. El suma del q'amaña alude a un "[con]vivir bien, no unos en contra de otros, o a costa de otros". Y como correlato, señala una relación con el Otro (miembro de una cultura distinta, parte de otra especie, con una naturaleza diferente) que no implica ni lucha ni explotación, como tampoco deseo de eliminar y/o dominar. Por el contrario, suma q'amaña supone convivencia con "mutua reciprocidad y afecto" (137) hacia todo lo que nos rodea. De donde se deriva la ética que subyace a esta forma particular de habitar/construir, la cual no busca, a costa de cualquier cosa o sujeto, la satisfacción de las necesidades propias. Tampoco persigue el bienestar por medio de la acumulación de bienes, siguiendo una lógica capitalista (Huanacuni Mamani 51).

Saenz lee a la urbe paceña de los 70 como expresión material de esta forma de habitar la ciudad al modo andino, al modo habitar/construir heideggeriano, a la manera suma q'amaña. Este habitar, sería así uno fundado en la coexistencia armónica con el entorno, produciría la ciudad de La Paz y 
esta ciudad nacida de este habitar haría a sus habitantes únicos. Esto hace a la urbe paceña mágica y prohíbe al progreso eliminar a su paso el buen vivir que produce.

[...] con una población integrada en su gran mayoría por aymaras y descendientes de aymaras, La Paz asume un carácter altamente diferenciado. Las influencias del mundo actual, con múltiples desarrollos tecnológicos que desafían y sobrepasan todo lo imaginable, y de cuyas corrientes difícilmente podríamos substraernos, encuentran natural resistencia en estas alturas, pues dichas influencias, aunque en algunos casos reportan beneficios, las más de las veces resultan nocivas, con normas, adelantos, divisas y aun costumbres que, decididamente, no concuerdan - por así decirlo- con nuestro modo de estar, y mucho menos con nuestro modo de ser. (11)

Como ya dijimos, tras el tono pesimista y desesperanzado usado por Saenz, está su insistencia en apuntar que la peculiaridad topográfica de La Paz, unida a su singularidad cultural, la ha convertido en punto de resistencia al embate de la Modernidad. Los productos tecnológicos modernos que conllevan e instauran marcos de pensamiento foráneo no consiguen cambiar al paceño del universo saenceano, que sin ser realmente aymara, adopta formas de pensar moldeadas por esta cultura, lo que hace posible detener la modernización y conservar "el espíritu vivo de todo cuanto de paceño aún existe" (22).

En realidad, Churubamba representa un verdadero punto crítico, el choque de dos modos de vida radicalmente distintos: Uno, dado al progreso y a todo lo nuevo, nutriéndose con la destrucción de lo viejo y construyendo febrilmente altos edificios y grandes avenidas, modernos hoteles y todo lo demás, y el otro, obstinadamente apegado a las viejas costumbres, oponiéndose al avance de lo nuevo y lo extraño, atesorando la fuerza siempre invencible de un pueblo que encuentra la razón de su existencia en las calles, en los patios y en las casas que le vieron nacer. (23)

En Churubamba, el primer barrio de La Paz, se halla la plaza Alonso de Mendoza, lugar de fundación de esta ciudad en la época colonial. ${ }^{10}$ En esta zona se atestigua el movimiento de transformación que está amputando el pasado paceño para proyectar a La Paz a un futuro, modernizarla. Como lugar de la

10 La ciudad de La Paz fue originalmente fundada en Laja el 20 de octubre de 1548 por Alonso de Mendoza. Días después fue trasladada a la localidad Chuquiago Marka por tener ésta un clima más templado. Allí se llevó a cabo la segunda fundación de esta urbe. 
fundación de la urbe paceña, Churubamba es parte del casco viejo, colonial, de la ciudad. Por eso, allí se plasma de una manera clara y gráfica el avance de la modernidad y la resistencia del pasado con su "histórica plaza", sus "empinadas calles y los tortuosos callejones" (25). La destrucción de casas coloniales y su reemplazo por edificios modernos, el ensanchamiento de calles para dar nacimiento a avenidas, no detiene el habitar del que hablamos antes. En Churubamba los habitantes ocupan el espacio instalando puestos de venta en las calles, amontonándose en la plaza, para rearticular los circuitos que el progreso pretende cambiar. Este barrio, por esto, es considerado por Saenz "EI corazón de la ciudad", lugar desde el cual se distribuye el flujo vital mágico de la ciudad social: "aquí confluyen y aquí se originan los afanes de unas trescientas o cuatrocientas mil almas, una mitad de la población total de La Paz" (23).

Otra expresión de este modo de habitar está en la calle Illampu. La descripción ofrecida por Saenz de lo que se encuentra en esta calle viene en forma de pregunta. Esto porque, por un lado, el destino de sus edificaciones es incierto $y$, por otro, porque el autor desea subrayar que este lugar es un enigma:

¿Qué pasa con las viejas casas de adobe, con paredes de un metro de espesor, con pesadas puertas, con grandes piezas para los viajeros, con cuatro y hasta cinco patios y con amplios poyos, con toda clase de facilidades para el manejo de la carga y con establos para las bestias?

¿Dónde paran ahora los viajeros a falta de los tambos que les ofrecían acogida? (41)

Si hay algo - desde el punto de vista saenceano- que diferencia a La Paz de otras ciudades es la presencia de pasajes comerciales que no son interiores sino principalmente exteriores, ubicados en espacios públicos y al aire libre. Esto impide el efecto de autoreflexión que Benjamin observa en los pasajes comerciales de París del siglo XIX, donde en las vitrinas se veían reflejados los vendedores, convirtiéndose en objetos de venta a la vez. ${ }^{11}$ Los

\footnotetext{
${ }^{11}$ Con referencia a la relación/oposición entre el interior y el exterior del espacio, Benjamin señala la importancia, en la urbe europea del siglo XIX, de lugares donde se hace despliegue de las mercancías ("Paris, the Capital of the Nineteenth Century" 96). En la ciudad de La Paz están los mercados públicos, los tambos, marcas de la paceñeidad para Saenz. No obstante, es necesario aclarar que el comercio en La Paz sigue un diseño distinto al de las urbes europeas en los 70, así como hoy en día. Ejemplo de esto es la Feria 16 de julio de la ciudad de El Alto, caracterizada por ser una feria de dimensiones
} 
lugares del texto de Saenz, todos espacios exteriores y públicos (calles, plazas, vecindarios, ríos, montañas, y los peatones que los hacen), no permiten que sus habitantes sean cooptados por la lógica del capital. El flujo de la vida paceña es el intercambio, pero no en tanto acumulación de objetos invalorables sino como circulación continua de mercancía y gente en áreas públicas.

En la calle Illampu estaban ubicados los tambos, lugares donde los productos venidos del campo eran depositados y puestos a la exposición para su venta a los intermediarios que después los llevaban a los diferentes mercados y tiendas de la ciudad. Esta calle era un punto de conexión entre el campo y la ciudad, entre los indígenas ubicados en la zona rural y aquellos migrantes ya asentados en la ciudad (la chola, el aparapita), donde se revelaba la co-dependencia socio-económica de estos mundos. Era, en fin, el lugar en donde confluyen calles, callejuelas, tambos, campo, ciudad, etc., regalando a los paceños un habitar orgánico con sus pares y con entidades no-humanas, como ser: riachuelos y montañas.

Este espacio que abierta y explícitamente revela aquello que hace mágica a La Paz, se desvanece ante nuestros ojos cuando el impulso moderno reemplaza a los tambos por "edificios de aspecto repulsivo llamados hoteles, esto es, una especie de casilleros de ladrillo que constituyen una vergüenza pública, construidos como le venga, a toda prisa y con muchos pisos, y con presuntuosidades que resultan grotescas en grado sumo" (41). En ese momento los viajeros indígenas que alimentan la ciudad no sólo con sus productos sino con su cultura, son obligados, por el progreso, a hundirse en las entrañas de la ciudad, convirtiéndose en ladrones y rufianes.

Algo distinto sucede con el Illimani, que también es artífice de la magia paceña. Este nevado, uno de los más altos de la cadena montañosa de los Andes, un volcán dormido, por su ubicación y dimensiones puede ser visto desde cualquier lugar dentro de la urbe paceña, deviniendo una suerte de referencia constante. Es una suerte de puntero gigante que señala al citadino sumido en su carrera diaria del hogar al trabajo, del trabajo al hogar, el cielo, lo que lo trasciende y por lo mismo le hace percibir su nimiedad y pequeñez. Paradójicamente, su proximidad y familiaridad hace también que el Illimani desaparezca para aquel citadino que no halla la pausa en su jornada para levantar la vista y dejarse llevar por el gran nevado a otras esferas.

casi inimaginables (parece infinita) y donde se despliegan todo tipo de mercancías, nuevas y usadas, tradicionales o novedosas, nacionales o internacionales, etc. 
Como se ha visto hasta aquí, las descripciones de lugares y retratos de personajes paceños elaborados por Saenz quieren mostrar las pulsiones mágicas que mueven la urbe paceña y que no van a permitir que se modernice. Los mismos tienen una apariencia inquietante por existir en los márgenes, en las profundidades y lugares invisibles, pero también por ser activa y constantemente ignorados. La reiterada queja de Saenz entonces recae en el hecho de que poco a poco la magia paceña se está volviendo más y más distante y oscura para sus habitantes, incluso para aquellos que habitan esta ciudad de un modo andino. Las páginas de Imágenes paceñas buscan por eso capturar ese instante del presente de la urbe paceña que el impulso del progreso está arrasando y poner al lector en contacto con lo que el flujo moderno ha dejado como extemporáneo: el mundo cultural andino que articula la urbe paceña.

\section{Mirar y leer no es convivir: la magia de la experiencia}

Imágenes paceñas es la única obra de Saenz que incluye soporte visual: el texto viene acompañado de imagen. Creemos importante explorar el singular y tenso diálogo que esta relación produce. Esto porque la misma agudiza la sensación de extrañeza que -como dijimos- sería una herramienta usada por Saenz para develar la magia de la urbe paceña. ${ }^{12} \mathrm{El}$ contrapunteo entre texto e imagen, en consecuencia, muestra la imposibilidad de captar y de capturar, por medio de la fotografía, la presencia de la ciudad sin habitarla.

Lejos de hacer visible lo que significa habitar La Paz, las fotografías, enfrentadas al lenguaje, abren un espacio ambiguo. Por una parte, nos permiten entrar en La Paz, aproximarnos a cada sitio descrito y visualizar cada personaje retratado. Por otra parte, las fotos operan de modo irónico. Ofrecen una representación de la ciudad pretendidamente realista a través del empleado de la tecnología moderna: la cámara fotográfica. Esto solo para hacer evidente la vacuidad de la imagen frente a la plenitud del texto escrito. La yuxtaposición entre la parte textual y las fotografías así genera una verdadera experiencia de La Paz para el lector, pues le deja vislumbrar lo oculto en la imagen bidimensional con el poder del lenguaje poético. Ahora bien, en

\footnotetext{
12 Es necesario aclarar, las fotografías incorporadas en Imágenes paceñas no son aquellas originalmente pensadas como soporte visual de la obra. Estas fotografías, tomadas por Javier Molina, fueron recortadas y modificadas en el proceso de edición y publicación del libro (ver entrevista con Javier Molina en este volumen). Sin embargo, el producto final, trabajo literario estudiado en este ensayo, produce el efecto anotado (una relación tensa entre texto e imagen) que pensamos Saenz perseguía.
} 
el proceso de leer y ver, los lectores arman su propio montaje. El libro actúa como una condensación material de la ciudad que cada lector tiene que habitar a su propio modo. La Paz no es sólo construida por Saenz y el fotógrafo, Molina, es también la posibilidad de experimentar la no-coincidencia entre imagen y lenguaje. Esto hace que los lectores habiten Imágenes paceñas.

Pensemos por ejemplo en la imagen asociada con la descripción del afilador:

\begin{abstract}
Al toque del instrumento de viento, que se deja escuchar a gran distancia [...] operando con mano diestra y en medio de súbito surtidor de chispas inofensivas y acariciadoras que saltan del esmeril, y que constituyen el encanto de los chicos, quienes acuden en tropel para contemplar la imagen de aquel que seguramente se les aparece con resplandores mágicos. (147)
\end{abstract}

La imagen que acompaña esta descripción (ver página 200) no consigue dar cuenta visual de aquello que la descripción de este personaje revela. Su habilidad para producir un efecto mágico con la máquina afiladora destinada a una función prosaica (afilar cuchillos) y la belleza de aquellas chispas "inofensivas y acariciadoras" que no encierran en sí el riesgo de la quemadura o del incendio, no son realmente capturados en la fotografía. Tampoco muestra a aquella multitud de niños, el público congregado por el afilador, que revolotean alrededor de este personaje maravillados por las chispas mágicas que produce. Pero la ausencia y el silencio de la imagen nos seducen en la medida en que causan un deseo incumplido - queremos ver aquello que el texto nos hace imaginar y, paradójicamente, nos acercan así a la experiencia auténtica del estar en uno de los lugares mágicos de La Paz o toparse con algún extravagante personaje paceño.

Lo mismo sucede con la fotografía que acompaña la descripción de un patio: "Una caterva de chicos juegan en el patio, chillan, patalean y lloran, y pelean como perros; ha de ser decididamente infernal la mucha bulla que meten, pero sin embargo aquí nadie parece notarlo" (115). El lector no encuentra a estos niños en la fotografía. Tampoco puede imaginar cómo se divierten y las disputas en las que están enredados. Ni qué decir de los vecinos. El lector no puede visualizar aquellos vecinos que pretenden ignorar el alboroto de los niños. Entonces, la divergencia entre la fotografía y el texto justamente señala los elementos del escenario que no pueden ser cooptados por la cámara fotográfica y que exigen la intervención del lector. El lector es obligado a habitar Imágenes paceñas como habitaría La Paz, creando una 


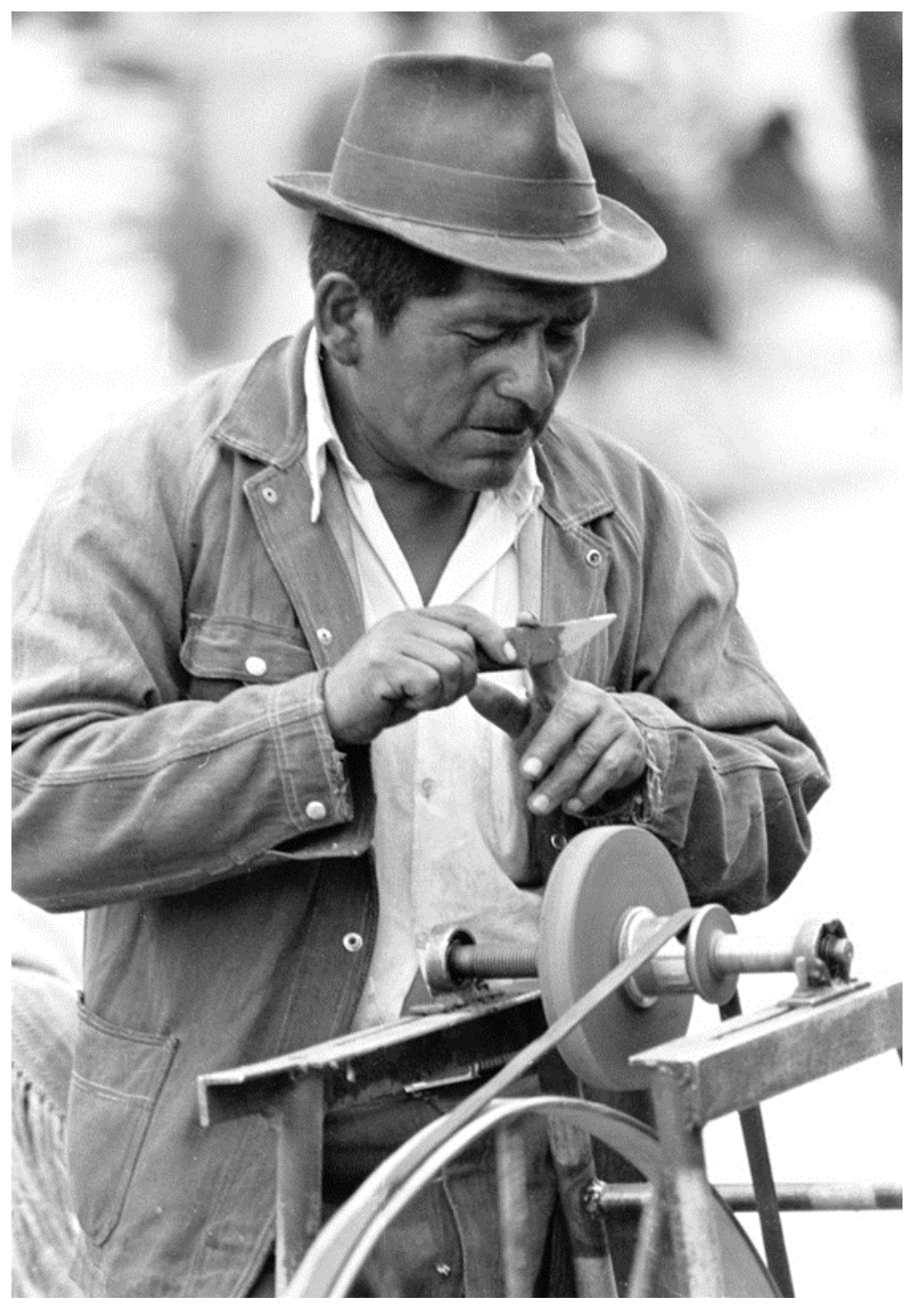

\section{El Afilador}

Fotografía: Javier Molina 
suerte de collage en su imaginación, para llenar los vacíos de la imagen con las sugerencias hechas por la voz narrativa. Nace entonces un campo magnético metafórico alrededor de lo que es habitar: estar en y ser hechura de La Paz.

Afirma Saenz que "[I]as influencias del mundo actual, con múltiples desarrollos tecnológicos que desafían y sobrepasan todo lo imaginable, y de cuyas corrientes difícilmente podríamos sustraernos, encuentran natural resistencia en estas alturas" (11). Esta "resistencia al desarrollo tecnológico" incluye la fotografía. La proliferación del uso de la fotografía durante la industrialización, según muchos críticos, es cómplice de las lógicas capitalistas de acumulación y reproducción, de decepción y manipulación. En la superficie, la fotografía permite la reproducción exacta de un momento en un espacio que parece estar congelado en un presente relativo $y$, por eso, nos da la sensación de revisitar el pasado.

En su ensayo "Little History of Photography", Walter Benjamin observa que:

The most precise technology can give its products a magical value, such as a painted picture can never again possess for us. No matter how artful the photographer, no matter how carefully posed his subject, the beholder feels an irresistible compulsion to search such a picture for the tiny spark of contingency, the here and now, with which reality has, so to speak, seared through the imagecharacter of the photograph, to find the inconspicuous place where, within the suchness [Sosein] of that long-past minute, the future nests still today - and so eloquently that we, looking back, may rediscover it. For it is another nature that speaks to the camera rather than to the eye; "other" above all in the sense that a space informed by human consciousness gives way to one informed by the unconscious. (276)

[La tecnología más precisa puede aportar un valor mágico a sus productos, lo que una pintura nunca puede poseer para nosotros. No importa el grado artístico del fotógrafo, ni con cuanto cuidado el sujeto posa, el observador siente una compulsion irresistible por buscar en esta imagen la chispa más minuciosa del azar, el aquí y ahora con que la realidad ha chamuscado, por así decirlo, su carácter de imagen, para encontrar el lugar inadvertido donde, dentro de la particularidad de ser de ese minuto ya muy pasado, anida el futuro $-\mathrm{y}$ tan elocuentamente que nosotros, mirando hacia atrás, podemos redescubrirlo. Porque la naturaleza que le habla a la cámara es distinta de la que habla a los ojos, "otra" sobre todo en sentido de que un espacio informado por la conciencia humana da paso a uno informado por el inconciente]. (Nuestra traducción) 
En la primera parte de esta cita, Benjamin habla del poder de la fotografía que nos permite imaginar el presente de aquel momento histórico - no el nuestro- y ponerlo en relación con el pasado y el futuro. El lector habita el texto, así, experimenta la ciudad por medio de este montaje. Acumula y organiza de manera arbitraria los retazos de la vida urbana paceña ofrecidos en Imágenes paceñas para (re)crear La Paz y, en el proceso, habitarla. La inclusión de soporte visual en esta obra no es casual, entonces. Saenz, por medio de la inclusión de imágenes, demuestra que es imposible conocer un lugar o un personaje a través de fotografías. El habitar es lo que hace la ciudad.

La aparente simpleza de la estructura de Imágenes paceñas: lista de "lugares" y "personas", subraya que no es posible separar estos componentes, así como el hecho de que ambos están determinados por un espacio y tiempo específicos. Lo que explica la paradoja: "la destrucción de una ciudad ha sido la verdadera causa de su definitiva permanencia", pues la disección de La Paz realizada por Saenz es solo un pretexto que moviliza el montaje desordenado de personas y lugares que propicia un habitar mágico de la ciudad. ${ }^{13}$

Un personaje que representa la idea de montaje de la propuesta saenceana es la emblemática figura del aparapita. Su saco, hecho de remiendos de distintas y variadas prendas y materiales (hilo, pita, cordel, cable eléctrico, guato de zapato, alambre o tiras de cuero), es una metáfora del abigarrado montaje que articula mundos culturales distintos, localidades diferentes, ciudad y campo, ritmos opuestos: la rapidez moderna y el estarse del aparapita. En Imágenes paceñas también coexisten y se sobreponen dos espacios, el altiplano y la ciudad, modos de vida aymaras y formas de existencia engendradas por la modernidad, el aquí y el allá, uno eje transcendental y otro capitalista. ${ }^{14}$ Este montaje refleja la abrupta y sorprendente irrupción de lo

\footnotetext{
13 La combinación de texto e imagen de Imágenes paceñas también dialoga con conceptos acuñados por René Zavaleta Mercado y Silvia Rivera Cusicanqui, "abigarramiento cultural" y "ch'ixi" respectivamente, que son empleados para definir a las sociedades bolivianas en la medida en que son resultado del amalgamiento de diferentes grupos culturales existiendo en y con distintas temporalidades. Saenz, en Imágenes paceñas, haría referencia de manera literaria a esta particular y curiosa realidad cultural que define a la ciudad de La Paz tanto por el contenido como por la forma.

14 Para una elaboración más detallada sobre los contrastes entre la aproximación transcendental a La Paz de Jaime Saenz y la materialista/anti-capitalista de Víctor Hugo Viscarra, ver el artículo de Irina Feldman, "Ruina/basural: Las lógicas temporales y espaciales de la ciudad de La Paz en Saenz y Viscarra” en este volumen (pags. 158-180).
} 
enterrado en el inconsciente colectivo, quebrando la apariencia uniforme moderna.

\section{Conclusión}

En resumen, este ensayo rastrea por qué una asociación en apariencia azarosa de ciertos lugares y personajes es para Saenz mágica. El texto denuncia el carácter corrosivo del progreso para hacer visible La Paz oculta, de donde provendrían sus poderes mágicos. Al hacerlo, presenta a la urbe paceña como resultado de la coexistencia de una pluralidad de sistemas de habitar, construir y nombrar el mundo. A pesar de las reiteradas declaraciones del autor sobre la inminente desaparición y destrucción de aspectos y personajes que hacen única a La Paz, Imágenes paceñas reproduce y reactualiza saberes y prácticas culturales aymaras. El espíritu mágico de La Paz, por eso, determina un modo de habitar que preserva conexiones e intercambios armónicos entre seres humanos de diferentes culturas y entidades no humanas. $Y$ aunque el texto se titula Imágenes paceñas, la magia no reside en la imagen (lo visible) sino más bien en generar un habitar con y en la ciudad.

En palabras de Saenz: "El espíritu que hoy nos anima a todos nosotros, habrá configurado de alguna manera la imagen de aquella ciudad que nos contempla ya en el futuro, en la que habremos de seguir existiendo en sus aires" (12). A pesar del tono nostálgico que emplea, Saenz apunta a la ciudad que está por venir, anticipando y confirmando la posibilidad del futuro de la urbe paceña andina que a él tanto maravilla. Sin caer en la especulación vacía, pensamos que La Paz de hoy compaginaría e incluso iría más allá de las ideaciones de Saenz. Basta con mirar la verticalidad del teleférico desde El Alto hacia abajo, que no deja de asombrar y posibilita sumergirse en la profundidad de la hoyada paceña del siglo XXI. Las costumbres que, pensaba Saenz, "mañana habrán desaparecido quizá", lejos de desvanecerse, han sido reforzadas en nuevas expresiones culturales. El Illimani, asimismo, se está; es todavía una presencia rectora de la ciudad andina moderna.

$\mathrm{Y}$, al honrado mago, la última palabra: "La Paz no ha muerto, y no morirá." 


\section{Bibliografía citada}

ALBÓ, Xavier. 2011. “Suma q'amaña: convivir bien. ¿Cómo medirlo?”. Vivir bien: ¿paradigma no capitalista? Ivone Farah y Luciano Vasapollo, cords. La Paz: CIDES, UMSA. 133-144.

AVELAR, Idelber. 2014. "Contemporary Intersections of Ecology and Culture: On Amerindian Perspectivism and the Critique of Anthropocentrism." Revista de Estudios Hispánicos. XLVIII (1): 105-121.

BENJAMIN, Walter, et al. 2008. "Little History of Photography". The Work of Art in the Age of its Technological Reproducibility and Other Writings on Media. Thomas Y. Levin, et al., eds. Edmund Jephcott et. al., trads. Cambridge, MA.: The Belknap Press of Harvard University Press. 274298.

---. 2008. "Paris, the Capital of the Nineteenth-Century". The Work of Art in the Age of its Technological Reproducibility and Other Writings on Media. Thomas Y. Levin, et al., eds. Edmund Jephcott et. al., trads. Cambridge, MA.: The Belknap Press of Harvard University Press. 96115.

---. 1969. “On Some Motifs in Baudelaire”. Illuminations. Hannah Arendt, ed., Harry Zohn, trad. New York: Schocken Books. 155-200.

Reproducido en Iluminaciones II. Baudelaire. Un poeta en el splendor del capitalismo. Jesús Aguirre, trad. Madrid: Tauros, 1972. 123-170

---. 1969. "Theses on the Philosophy of History". Illuminations. Hannah Arendt, ed., Harry Zohn, trad. New York: Schocken Books. 253-264.

---. 1969. "The Work of Art in the Age of Mechanical Reproduction". Illuminations. Hannah Arendt, ed., Harry Zohn, trad. New York: Schocken Books. 217-251.

COHEN, Margaret. 1995. Profane Illumination: Walter Benjamin and the Paris of Surrealist Revolution. Berkeley, CA.: University of California Press.

GONZÁLEZ CASANOVA, Pablo. 1963. "Sociedad plural, colonialismo interno y Desarrollo". América Latina 6 (3): 15-32.

HEIDEGGER, Martin. 2016 [1951]. Construir, habitar, pensar. Francisco Soler, trad. Teoría 5-6. 150-162.

[https://revistas.uchile.cl/index.php/TRA/article/view/41564/43080] página descargada el 15 de septiembre, 2021.

HUANACUNI MAMANI, Fernando. 2010. Vivir bien/buen vivir: filosofía, políticas, estrategias y experiencias regionales. 1a. ed. La Paz: Convenio Andrés Bello.

KRISTEVA, Julia. 1991. Stranger to Ourselves. Leon S. Roudiez, Trad. New York: Columbia University Press.

MONASTERIOS PÉREZ, Elizabeth. 2001. Dilemas de la poesía del fin de siglo: José Emilio Pacheco y Jaime Saenz. La Paz: Plural.

QUIJANO, Aníbal. 2007. "Colonialidad del poder, globalización y democracia". Diplomacia, Estrategia y Política. 6. 133-181. [http://www.funag.gov.br/ipri/images/pdf/Revista_DEP06_Espanhol.p df] página descargada el 15 de septiembre, 2021. 
RAMA, Ángel. 2009 [1984]. La ciudad letrada. Ciudad de México, México: Fineo.

RIVERA CUSICANQUI, Silvia. 2015. Sociología de la imagen: Miradas ch'ixi desde la historia andina. Buenos Aires: Tinta Limón.

SAENZ, Jaime. 1979. Imágenes paceñas: Lugares y personas de la ciudad. La Paz: Difusión.

SANJINÉS, Javier. 2003. "A Phenomenological Reading of the Andes: Toward the Desublimation of the Cholo." Guttorm Fløistad, ed. Contemporary philosophy. 8. Philosophy of Latin America. Dordrecht : Kluwer Academic. 171-185.

WOLFENZON, Carolyn. 2015. "La figura del aparapita en Felipe Delgado de Jaime Sáenz: nacionalismo, misticismo y conflicto social". Chasqui 44 (2): 241-257. [https://go-galecom.pitt.idm.oclc.org/ps/i.do?p=LitRC\&u=upitt_main\&id=GALE\%7CA4 $35451478 \& v=2.1 \& i t=r]$ página descargada el 15 de septiembre 2021.

YAMPARA HUARACHI, Simón. 2011.“Convivencia andina: vivir y convivir en armonía integral - Suma qamaña" Bolivian Studies Journal 18. 1-22.

ZAVALETA MERCADO, René. 1990. La formación de la conciencia nacional. Cochabamba, Bolivia: Los Amigos del Libro.

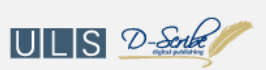

New articles in this journal are licensed under a Creative Commons Attribution 4.0 United States License.

This journal is published by the University Library System of the University of Pittsburgh as part of its D-Scribe Digital Publishing Program, and is cosponsored by the University of Pittsburgh Press. 